\title{
The European quality labels in chemical sciences: applying the Tuning Methodology in quality assurance
}

\author{
Evangelia A. Varella
}

\begin{abstract}
The European Chemistry Thematic Network is a non-profit making association focused on enhancing the quality and harmonising the features of chemical education and training all over the European Higher Education Area. In the context of quality assurance, it developed European Quality Labels in Chemical Sciences, which were initiated in the frame of the Tuning project, and are following the Tuning methodology. The Labels are awarded to programmes on chemistry or related disciplines, as well as to studies at the interface of chemistry and other subjects. They are based on the Budapest Cycle Level Descriptors, a detailed adaptation of the Dublin Descriptors for the field of chemical sciences. The following aspects are considered in awarding Eurobachelor ${ }^{\circledR}$ and Euromaster ${ }^{\circledR}$ Labels: learning outcomes, including subject knowledge, abilities and skills; modularisation of courses and contents; ECTS credit distribution and student workload; mobility; methods of teaching and learning; assessment; quality assurance. For the Chemistry Doctorate Eurolabel ${ }^{\circledR}$ the considerations are somehow different and include: fitness for purpose; entry to the programme; length of studies; study programme structure; teaching and training in generic competences; transcripts; graduate schools; supervision; examinations; assessment; and quality assurance. The Chemistry Short Cycle Eurolabel ${ }^{\circledR}$ refers to study programmes, which are placed at Level 5 in the in the European Qualifications Framework for Lifelong Learning, and are also seen as an intermediate level within or linked to the first cycle of the Qualifications Framework for the European Higher Education Area. Aspects considered are analogous to those mentioned for the Eurobachelor ${ }^{\circledR}$ Label.
\end{abstract}

Keywords: European Chemistry Thematic Network; chemical sciences; Budapest descriptors; quality assurance; European quality labels; short cycle.

\section{The European Chemistry Thematic Network}

The European Chemistry Thematic Network ${ }^{1}$ is a non-profit making association registered in Belgium, and is the outcome of seventeen years of networking activities focused on enhancing the quality and harmonising the features of chemical education and training all over the European Higher

\footnotetext{
1 "European Chemistry Thematic Network," http://ectn-assoc.cpe.fr/.
} 
Education Area. ${ }^{2}$ Academic institutions, national chemical societies, and stakeholders comprise the over 130 members coming from thirty European countries, and with associate members worldwide.

The statutory aims and objectives of the European Chemistry Thematic Network are:

- To implement, consult or supervise programmes for the assessment of skills and knowledge in chemical sciences.

- To undertake programmes concerning education and training, especially those concerning innovative approaches.

- To operate as a consultant or assessor in programmes concerning education and training.

- To provide certification of achievement when assessments have been carried out under appropriate conditions.

- To cooperate with established professional or other associations in the furtherance of its objectives.

- To extend the reach of all aspects of education in science and engineering beyond national borders.

- To provide a European framework for degrees in chemistry and related disciplines.

In order to proceed towards realisation of these goals, the European Chemistry Thematic Network is operating through pertinent committees in four closely interconnected areas, namely distance education, intensive learning, recuperation of a positive image for chemistry, and quality assurance.

\section{The European Quality Labels in Chemistry}

In the context of quality assurance, the Thematic Network developed European Quality Labels in Chemical Sciences. They were initiated in the frame of the Tuning project, and are following the Tuning methodology.

The European Quality Labels are awarded to programmes on chemistry or related disciplines, as well as to studies at the interface of chemistry and other subjects; and are particularly important for assuring the quality of transnational consortia of institutions. Their primary aim is to provide degrees, which will be automatically recognised by other institutions within the

${ }^{2}$ European Commission, "Bologna Process - European Higher Education Area," http:// www.ehea.info/. 
countries implicated in the Bologna Process, ${ }^{3}$ promoting thus mobility and employability prospects for new graduates. The Quality Labels have been adopted by the European Association for Chemistry and Molecular Sciences. ${ }^{4}$

Evaluation procedures are monitored by a Label Committee, consisting of a Chair, an Executive Secretary and a maximum of seven ordinary members. The Chair and Executive Secretary are nominated by the Administrative Council of the European Chemistry Thematic Network, while members are elected by the association's General Assembly. In all cases nomination or election is initially for a period of two years. The Chair can be confirmed in office by the Administrative Council for one further twoyear period. The Executive Secretary can be confirmed in office by the Administrative Council for an unlimited number of further two-year periods. One half of the ordinary members must be replaced every two years by election on a rotation principle taking into account national distribution.

The Label Committee maintains a Register of trained experts who carry out the processes of accreditation. The Register of Experts has been established, asking those handling EuroLabe ${ }^{\circledR}$ applications to be registered as a European Chemist, ${ }^{5}$ or have an equivalent qualification; and designing somehow higher standards for Chemistry Doctorate Eurolabel ${ }^{\circledR}$ experts. Online and face-to-face training opportunities are openly available. Site visit teams are recruited form the Register. In addition, evaluators for the Chemistry Doctorate Eurolabel ${ }^{\circledR}$ should have research interests related to the subject of the doctoral programme.

The European Quality Labels are based on the Budapest Cycle Level Descriptors, ${ }^{6}$ a detailed adaptation of the Dublin Descriptors ${ }^{7}-$ generic descriptors adopted by the European Ministers Responsible for Higher

${ }^{3}$ European Commission, "Bologna Process - European Higher Education Area. How does the Bologna Process work?," http://www.ehea.info/article-details .aspx? ArticleId=5.

4 "European Association for Chemical and Molecular Sciences," http://www euchems. eu/about.html.

5 "European Association for Chemical and Molecular Sciences - European Chemist Designation," http://www.euchems.eu/nc/members/european-chemist.html?sword_ list $\% 5 \mathrm{~B} \% 5 \mathrm{D}=$ chemist.

${ }^{6}$ Tuning Project, "Reference Points for the Design and Delivery of Degree Programmes in Chemistry," http://www.unideusto.org/tuningeu/images/stories/Publications/ CHEMISTRY_FOR_WEBSITE.pdf;

European Chemistry Thematic Network, "Recommendations for the Third Cycle," http://ectn-assoc.cpe.fr/chemistry-eurolabels/doc/officials/Off_EDL061017_ Eurodoctorate200611V1.pdf.

${ }^{7}$ European Commission, "The Framework of Qualifications for the European Higher Education Area - Dublin Descriptors," http://www .ehea.info/Uploads/Documents/QF-EHEAMay2005.pdf. 
Education, ${ }^{8}$ and forming the basis of the Qualifications Framework for the European Higher Education Area ${ }^{9}$ - for the field of chemical sciences. The Budapest descriptors dealing with the three cycles of university studies were developed by the members of the European Chemistry Thematic Network forming the Chemistry Subject Area group in the Tuning project. For the short cycle, the Budapest descriptor was developed by the European Chemistry Thematic Network and the project European Chemistry and Chemical Engineering Educational Network.

In order to better align with further the European bodies awarding Quality Labels, the European Chemistry Thematic Network is a founding member and holds the vice-presidency of the European Alliance for SubjectSpecific and Professional Accreditation and Quality Assurance (EASPA). ${ }^{10}$

\section{The Eurobachelor ${ }^{\circledR}$ Quality Label}

The Eurobachelor ${ }^{\circledR}$ Quality Label has been designed and implemented by the Subject Specific Group in Chemistry, Tuning project, and the Eurolabel Committee, European Chemistry Thematic Network.

All degree programmes holding the Eurobachelor ${ }^{\circledR}$ Quality Label ${ }^{11}$ are learning-outcome-based. Each institution is free to decide on the length of studies within the frame of 180-240 credits, as understood in the European Credit Transfer and Accumulation System (ECTS); ${ }^{12}$ as well as on the content, nature and organisation of courses, provided that students become conversant with the main aspects of chemistry, and develop a wide range of competences. Hence, at least 150 ECTS credits should deal with chemistry, physics, biology or mathematics, a thesis or industrial placement equivalent to 15 ECTS credits incorporated. In addition, at least 90 ECTS credits should be allocated to compulsory modules on organic chemistry, inorganic chemistry, physical chemistry, and analytical chemistry. Further modules should be of three types - compulsory, semi-optional, and elective.

${ }^{8}$ European Commission, "The European Higher Education Area - Achieving the Goals (Bergen 2005)," http://www.ehea.info/Uploads/Declarations/Bergen_Communique1.pdf.

9 European Commission, "A Framework for Qualifications of the European Higher Education Area," http://www .ehea.info/Uploads/qualification/050218_QF_EHEA.pdf.

10 "European Alliance for Subject-Specific and Professional Accreditation and Quality Assurance," http:www .easpa.eu.

${ }^{11}$ European Chemistry Thematic Network, “The Chemistry “Eurobachelor ${ }^{\circledR}$," http://ectnassoc.cpe.fr/chemistry-eurolabels/doc/officials/Off_EBL070131_Eurobachelor_ Framework_2007V1.pdf.

${ }_{12}$ European Commission, "European Credit and Accumulation System," http://ec.europa. eu/education/tools/ects_en.htm. 
The following aspects are considered in the Eurobachelor ${ }^{\circledR}$ Label:

- Learning outcomes, including subject knowledge, as well as abilities and skills - chemistry-related cognitive abilities and skills, chemistryrelated practical skills, generic and transferable competences.

- Modularisation of courses and contents.

- ECTS credit distribution.

- Student workload.

- Mobility.

- Methods of teaching and learning.

- Assessment and grading.

- Quality assurance.

Learning outcomes are founded on the relevant Budapest Descriptor, reading as follows:

First cycle degrees in chemistry are awarded to students who have shown themselves by appropriate assessment to:

- Have a good grounding in the core areas of chemistry: inorganic, organic, physical, biological and analytical chemistry; and in addition the necessary background in mathematics and physics.

- Have basic knowledge in several other more specialised areas of chemistry, such as computational chemistry, materials chemistry, macromolecular chemistry, radiochemistry.

- Have built up practical skills in chemistry during laboratory courses, at least in inorganic, organic and physical chemistry, in which they have worked individually or in groups as appropriate to the area.

- Have developed generic skills in the context of chemistry which are applicable in many other contexts.

- Have attained a standard of knowledge and competence which will give them access to second cycle course units or degree programmes.

Such graduates will:

- Have the ability to gather and interpret relevant scientific data and make judgements that include reflection on relevant scientific and ethical issues.

- Have the ability to communicate information, ideas, problems and solutions to informed audiences. 
- Have competences which fit them for entry-level graduate employment in the general workplace, including the chemical industry.

- Have developed those learning skills that are necessary for them to undertake further study with a sufficient degree of autonomy.

Subject knowledge comprises at least the subsequent issues: major aspects of chemical terminology, nomenclature, conventions and units; the major types of chemical reaction and the main characteristics associated with them; the principles and procedures used in chemical analysis and the characterisation of chemical compounds; the characteristics of the different states of matter and the theories used to describe them; the principles of quantum mechanics and their application to the description of the structure and properties of atoms and molecules; the principles of thermodynamics and their applications to chemistry; the kinetics of chemical change, including catalysis; the mechanistic interpretation of chemical reactions; the characteristic properties of elements and their compounds, including group relationships and trends within the Periodic Table; the structural features of chemical elements and their compounds, including stereochemistry; the properties of aliphatic, aromatic, heterocyclic and organometallic compounds; the nature and behaviour of functional groups in organic molecules; major synthetic pathways in organic chemistry, involving functional group inter conversions and carbon-carbon and carbon-heteroatom bond formation; the relation between bulk properties and the properties of individual atoms and molecules, including macromolecules (both natural and man-made), polymers and other related materials; the structure and reactivity of important classes of bio molecules and the chemistry of important biological processes.

Chemistry-related cognitive abilities and skills considered necessary are: ability to demonstrate knowledge and understanding of essential facts, concepts, principles, and theories relating to the defined subject knowledge; ability to apply such knowledge and understanding to the solution of qualitative and quantitative problems of a familiar nature; skills in the evaluation, interpretation, and synthesis of chemical information and data; ability to recognise and implement good measurement science and practice; skills in presenting scientific material and arguments in writing and orally, to an informed audience; computational and data processing skills, relating to chemical information and data.

Required chemistry-related practical skills encompass: skills in the safe handling of chemical materials, taking into account their physical and chemical properties, including any specific hazards associated with their use; skills required for the conduct of standard laboratory procedures involved and use of instrumentation in synthetic and analytical work, in relation to both organic and 
inorganic systems; skills in the monitoring, by observation and measurement, of chemical properties, events or changes, and the systematic and reliable recording and documentation thereof; ability to interpret data derived from laboratory observations and measurements in terms of their significance and relate them to appropriate theory; ability to conduct risk assessments concerning the use of chemical substances and laboratory procedures.

Finally, essential generic and transferable competences deal with: the capacity to apply knowledge in practice, in particular problem-solving competences, relating to both qualitative and quantitative information; numeracy and calculation skills, including such aspects as error analysis, order-of-magnitude estimations, and correct use of units; informationmanagement competences, in relation to primary and secondary information sources, including information retrieval through on-line searches; ability to analyse material and synthesise concepts; information-technology skills such as word-processing and spread sheet use, data-logging and storage, subjectrelated use of the Internet; the capacity to adapt to new situations and make decisions; skills in planning and time management; interpersonal skills, relating to the ability to interact with other people and to engage in teamworking; communication competences, covering both written and oral communication in both one of the major European languages (English, French, German, Italian, Spanish) and the language of the home country; study competences needed for continuing professional development, in particular the ability to work autonomously; ethical commitment.

\section{The Euromaster ${ }^{\circledR}$ Quality Label}

The Euromaster ${ }^{\circledR}$ Quality Label has been designed and implemented by the Subject Specific Group in Chemistry, Tuning project, and the Eurolabel Committee, European Chemistry Thematic Network.

The Euromaster ${ }^{\circledR}$ Quality Label ${ }^{13}$ is awarded to programmes involving 90 to 120 ECTS credits, at least 60 of which must be at master's level. Since second cycle studies are much more flexible than first cycle ones, it is neither necessary nor advisable to list areas of subject knowledge, which the programme should cover. According to the needs of the institution, such programmes will be either broadly-based or specialised. The master's thesis, however, should carry at least 30 ECTS credits.

${ }^{13}$ European Chemistry Thematic Network, "The Chemistry "Euromaster ${ }^{\circledR}, "$ http://ectnassoc.cpe.fr/chemistry-eurolabels/doc/officials/Off_EML060930_Euromaster_ Framework_200609V1a.pdf. 
The following aspects are considered in the Euromaster ${ }^{\circledR}$ Label:

- Learning outcomes, including subject knowledge, as well as abilities and skills - chemistry-related cognitive abilities and skills, chemistryrelated practical skills, generic and transferable competences.

- Modularisation of courses and contents.

- ECTS credit distribution.

- Student workload.

- Mobility.

- Methods of teaching and learning.

- Assessment and grading.

- Quality assurance.

Although the institution can define the appropriate subject knowledge for its own individual degree programme, abilities and skills are carefully monitored, since students may come from a different undergraduate background.

Learning outcomes are founded on the relevant Budapest Descriptor, reading as follows:

Second cycle degrees in chemistry are awarded to students who have shown themselves by appropriate assessment to:

- have knowledge and understanding that is founded upon and extends that of the Bachelor's level in chemistry, and that provides a basis for originality in developing and applying ideas within a research context;

- have competences which fit them for employment as professional chemists in chemical and related industries or in public service; and

- have attained a standard of knowledge and competence which will give them access to third cycle course units or degree programmes.

Such graduates will:

- have the ability to apply their knowledge and understanding, and problem solving abilities, in new or unfamiliar environments within broader (or multidisciplinary) contexts related to chemical sciences;

- have the ability to integrate knowledge and handle complexity, and formulate judgements with incomplete or limited information, but that include reflecting on ethical responsibilities linked to the application of their knowledge and judgements;

- have the ability to communicate their conclusions, and the knowledge and rationale underpinning these, to specialist and non-specialist audiences clearly and unambiguously; and 
- have developed those learning skills that will allow them to continue to study in a manner that may be largely self-directed or autonomous, and to take responsibility for their own professional development.

Indispensable chemistry-related cognitive abilities and skills encompass, in addition to those requested for the first-cycle level: ability to demonstrate knowledge and understanding of essential facts, concepts, principles and theories relating to the subject areas studied during the master's programme; ability to apply such knowledge and understanding to the solution of qualitative and quantitative problems of an unfamiliar nature; ability to be able to adopt and apply methodology to the solution of unfamiliar problems.

Further chemistry-related practical skills considered necessary include: competences required for the conduct of advanced laboratory procedures and use of instrumentation in synthetic and analytical work; ability to plan and carry out experiments independently and be self-critical in the evaluation of experimental procedures and outcomes; ability to take responsibility for laboratory work; ability to use an understanding of the limits of accuracy of experimental data to inform the planning of future work.

Finally, essential generic and transferable competences deal with: study skills needed for continuing professional development; ability to interact with scientists from other disciplines on inter- or multidisciplinary problems; ability to assimilate, evaluate and present research results objectively; advanced communication competences in a second European language, along with the mother tongue.

\section{The Chemistry Doctorate Eurolabel ${ }^{\circledR}$}

The Chemistry Doctorate Eurolabel ${ }^{\circledR}$ has been designed and implemented in the frame of the project: A Framework for a Third Cycle Qualification in Chemistry, in co-operation with the European Chemistry Thematic Network.

As a framework for a third cycle qualification, the Chemistry Doctorate Eurolabe ${ }^{\circledR 14}$ interests institutions which have introduced structured doctoral programmes in chemical sciences or interdisciplinary topics based on chemistry. It is fostering quality assurance for doctoral degrees in chemistry, is promoting mobility at a global level, and is guaranteeing harmonisation and transparency towards the research community and the labour market.

${ }^{14}$ Chemistry Doctorate Eurolabel ${ }^{\circledR}$ Project, “A Framework for a Third Cycle Qualification in Chemistry," http://www.phdchem.eu. 
The following aspects are considered in the Chemistry Doctorate Eurolabel $^{\circledR}$ :

- Fitness for purpose.

- Entry to the programme.

- Length of studies.

- Study programme structure, i.e. coursework and credits considered in the widest possible sense.

- Teaching and training in generic competences.

- Transcripts.

- Graduate schools.

- Supervision.

- Examinations.

- Assessment.

- Quality assurance.

The qualification is awarded on the basis of the relevant Budapest Descriptor, reading as follows:

Third cycle (doctoral) degrees in chemistry are awarded to students who

- have demonstrated a systematic understanding of an aspect of the science of chemistry and mastery of those skills and methods of research associated with the topic of this research;

- have demonstrated the ability to conceive, design, implement and develop a substantial process of research in chemical sciences with rigour and integrity;

- have made a contribution through original research that extends the frontier of knowledge in chemical science by developing a substantial body of work, some of which merits national or international refereed publication; and

- have competences which fit them for employment as professional chemists in senior positions in chemical and related industries and in public service, or for a progression to a career in academic research.

Such graduates

- are capable of critical analysis, evaluation and synthesis of new and complex ideas;

- can communicate with their peers, the larger scholarly community and with society in general about their areas of expertise; and 
- can be expected to be able to promote, within both academic and professional contexts, scientific and technological advancement in a knowledge based society.

The means used for acquiring key competences - during research work or in the context of specialised workshops and course units - are given an important place in the frame of the Quality Label, since they are crucial for entering the labour market; and are addressing environments candidates are likely to meet during any forthcoming career connected to their qualifications. They presume original, independent and critical thinking, and read as follows: The planning process - objectives, strategies, policies, decision making; the structure and process of organising - authority $v s$. self-contained work, organisational flexibility, adaptability to novel situations, time management; the management of human resources - qualifications $v s$. requirements, orienting new team members, team building, organising individual tasks and duties, formulating motivation strategies; the management of information - analysis, evaluation, synthesis and selection of complex concepts and facts; the communication process - communication skills (including presentation techniques, language skills, writing of proposals and reports); tutoring and training skills; ability for knowledge transfer and interaction under multilingual conditions with peers, audiences $\&$ panels, the scholarly community and society in general; the development process internal and external training, handling innovation; the management of financial issues - facing budgetary and market-oriented questions, dealing with budgetary restrictions; the process of controlling and assessing quality; social responsibility and ethics.

The relevant Budapest Descriptor illustrates the goals of a doctoral programme in chemical sciences, and applicants are asked to provide a statement defining the aims and profile of the programme; and describing the skills and competences, which the graduate will have developed at the end of the programme. The accreditation process is then designed to find out whether the programme as set out in detail in the application is suitable for the purpose for which it is designed.

\section{The Chemistry Short Cycle Eurolabel ${ }^{\circledR}$}

The Chemistry Short Cycle Eurolabe $l^{\circledast}$ has been designed and implemented in the frame of the project: European Chemistry and Chemical Engineering Education Network, in co-operation with the European Chemistry Thematic Network. 
In the Leuven/Louvain-la-Neuve Communiqué (2009), ${ }^{15}$ the European ministers responsible for Higher Education stated that: higher education is being modernised with the adoption of a three-cycle structure including, within national contexts, the possibility of intermediate qualifications linked to the first cycle. They further anticipated that: within national contexts, intermediate qualifications within the first cycle can be a means of widening access to higher education.

Three years later, in the Bucharest Communique $(2012)^{16}$ the ministers agreed to: explore how the QF-EHEA could take account of short cycle qualifications (EQF Level 5) and encourage countries to use the QF-EHEA for referencing these qualifications in national contexts where they exist. To this aim, they committed themselves to: explore how the QF-EHEA could take account of short cycle qualifications in national contexts, at the European level, in preparation of the Ministerial Conference in 2015 and together with relevant stakeholders.

The Chemistry Short Cycle Eurolabel ${ }^{\circledR}$ is addressing the need of evaluating intermediate qualifications linked to the first cycle in the area of chemical sciences and chemical technology at a European level, in order to assist widening access to higher education in the Bologna Process signatory countries. The Quality Label refers to study programmes, which are placed at Level 5 in the European Qualifications Framework for Lifelong Learning, ${ }^{17}$ and are also seen as an intermediate level within or linked to the first cycle of the Qualifications Framework for the European Higher Education Area; and which are organised by universities, colleges, centres for adult education, or even upper secondary schools. Primary aim of the qualification is to provide a short cycle degree which will be recognised by other European institutions as being of a standard providing automatic right of access to further studies within first cycle programmes in chemical sciences, and ensuring recognition of knowledge and competences obtained during short cycle studies.

Curricula purely dealing with chemical sciences are not often encountered in short cycle higher education. nevertheless, topics related to chemistry and chemical technology are frequently included in study programmes dealing with bio technics, environmental studies, restoration, agriculture, domestic sciences, engineering, health care, and product development.

${ }^{15}$ European Commission, "The Bologna Process 2020 - The European Higher Education Area in the New Decade (Leuven/Louvain-la-Neuve 2009)," http://www .ehea.info/Uploads/ Declarations/Leuven_Louvain-la-Neuve_Communiqu\%C3\%A9_April_2009.pdf.

${ }^{16}$ European Commission, "Making the Most of Our Potential: Consolidating the European Higher Education Area (Bucharest 2012), " http://www .ehea.info/Uploads/\%281\%29/ Bucharest\%20Communique\%202012\%281\%29.pdf.

${ }_{17}$ European Commission, "European Qualifications Framework for Lifelong Learning," http://ec.europa.eu/eqf/home_en.htm. 
In order to evaluate study programmes with regard to the Budapest Descriptor for the Short Cycle, it is of outmost importance to specify the educational input and learning outcomes considered necessary for Level 5 in the European Qualifications Framework for Lifelong Learning. For the short cycle, subject knowledge and subject-related competences are practically based and occupationally specific. They build upon general secondary education and are at a level supported by advanced textbooks; and offer comprehensive, specialised, factual and theoretical knowledge within the field of study, as well as a comprehensive range of cognitive and practical skills required to develop creative solutions to abstract problems. Their aim is to prepare students to enter the labour market, or to provide pathways to other tertiary education programmes.

In the frame of chemical sciences, subject knowledge refers to the main areas of chemistry, as well as to mathematics and physics. Practical skills, which are acquired during laboratory courses, should include exercises in inorganic, organic and physical chemistry. Taking into account the abovecited frame, the Budapest Descriptor for the short cycle reads as follows:

Qualifications that signify completion of the short cycle (within or linked to the first cycle) in chemistry are awarded to students who

- have a good grounding in the main areas of chemistry, especially analytical chemistry; and in addition the necessary background in mathematics and physics. This fundamental knowledge should be practically based and occupationally specific, and built upon general secondary education at a level requiring the support of advanced educational material;

- have basic knowledge in several other more specialised areas of chemical sciences and/or chemical technology, as related to their particular field of study;

- have built up practical skills in chemical sciences and/or chemical technology during laboratory courses, in which they have worked individually or in groups as appropriate to the area. Although chiefly relevant to each particular field of study, laboratory courses should include exercises in inorganic, organic and physical chemistry;

- have developed generic skills in the context of chemistry which are applicable in many other contexts; and

- have attained a standard of comprehensive, specialised, factual and theoretical knowledge and competence which will allow them to continue studies in order to complete the first cycle. 


\section{Such graduates will}

- have the ability to identify and use data to formulate creative responses to well-defined concrete and abstract scientific problems and ethical issues;

- have the ability to communicate about their understanding, skills and activities with peers, supervisors, clients and any informed audience;

- have competences which fit them for practically based, occupationally specific, performance related employment in the general chemistryrelated workplace, including the chemical industry; and

- have developed those learning skills that are necessary for them to undertake further studies with some autonomy.

The expected outcomes of a short cycle study programme are described by the appropriate Budapest Descriptor, which forms the basis of the qualification. The Label is based on 120 ECTS credits. Nevertheless, it may be used to accredit programmes leading to short cycle degrees, and equivalent to 150 or even 180 ECTS credits. In this case, all requisites of the two year programme have to be met, and the remaining modules are considered as an added value to the curriculum.

Institutions providing short cycle programmes of the proposed type are completely free to decide on the content, nature and organisation of courses or modules. The depth, in which individual aspects are treated, will vary with the nature of specific programmes. The Label asks for a minimum of 90 ECTS credits for modules dealing with the main areas of chemistry, as well as physics and mathematics. Within these 90 credits, at least 30 should correspond to compulsory modules. The remaining 60 (or less) will typically focus on a particular field of study, and correspond to fully applied modules, which will assist students in developing specific chemistry-related cognitive abilities and practical skills intended to foster their expertise in a welldefined discipline. The remaining ECTS credits are freely allocable.

Concerning chemical sciences, subject knowledge refers to the main areas of chemistry, as well as to physics and mathematics. Subject-specific competences include cognitive abilities and skills related to chemical sciences and chemical technology, and involving intellectual tasks; and practical skills, typically involving the conduct of laboratory work in analogous topics. Furthermore, every curriculum should intrinsically develop key competences of a general nature, applicable in many other contexts.

In the frame of the Quality Label, it is suggested to ensure that students become conversant with the main aspects of chemistry, and develop the main abilities and competences expected by the end of a short cycle programme. It 
should be made clear that the learning outcomes listed in the following paragraphs are intended to be indicative rather than a prescription to be adopted word-by-word across all relevant curricula.

Subject knowledge comprises at least the subsequent issues: major aspects of chemical terminology, nomenclature and units; major types of chemical reactions and the main characteristics associated with them; basic procedures used in chemical analysis and the characterisation of chemical compounds; basic concepts of instrumentation; characteristics of the different states of matter and theories used to describe them; fundamental aspects of the structure and properties of atoms and molecules; basic principles of thermodynamics and their applications to chemistry; basic kinetics of chemical change, including catalysis; characteristic properties of elements and their compounds; fundamental notions of stereochemistry; characteristic properties of organic compound classes; standard reactions in organic chemistry.

Indispensable chemistry-related cognitive abilities and competences encompass: ability to demonstrate knowledge and understanding of welldefined facts, concepts, principles and theories relating to the subject areas identified above; ability to apply such knowledge and understanding to the solution of standard qualitative and quantitative problems of a familiar nature; competences in the evaluation, interpretation and synthesis of uncomplicated chemical information and data referring to taught subjects; ability to recognise and implement basic measurement science and practice; competences in presenting well-defined scientific material, in writing and orally, to an informed audience; basic computational and data-processing skills, relating to chemical information and data.

Chemistry-related practical skills considered necessary are: skills in the safe handling of chemical materials, taking into account their physical and chemical properties, including any specific hazards associated with their use; skills required for the conduct of standard laboratory procedures and operation of broadly used instruments in synthetic and analytical work, in relation to both organic and inorganic systems, and referring to well-defined topics in the frame of the subject areas identified above; skills in the monitoring, by observation and measurement, of chemical properties, events or changes related to well-defined topics in the frame of the subject areas identified above, and the systematic and reliable recording and documentation thereof; ability to collect data derived from standard laboratory observations and measurements; ability to conduct risk assessments concerning the use of chemical substances and laboratory procedures related to well-defined topics in the frame of the subject areas identified above. 
In addition, essential generic and transferable competences deal with: the capacity to apply knowledge in practice, in particular problem-solving competences, relating to both qualitative and quantitative information; numeracy and calculation skills, including such aspects as order-of-magnitude estimations and correct use of units; information-management competences, in relation to primary and secondary information sources, including information retrieval through on-line computer searches; ability to analyse material on well-defined topics; the capacity to adapt to new situations; information-technology skills, such as word-processing and spread sheet use, data-logging and storage, subject-related use of the internet; basic skills in planning and time management; interpersonal skills, relating to the ability to interact with other people and to engage in team-working; basic communication competences, covering both written and oral communication, in one of the major European languages (English, German, Italian, French, Spanish), as well as in the language in which the study programme is delivered; study competences needed for continuing professional development, including in particular the ability to handle work situations with a certain degree of autonomy; ethical commitment.

\section{Conclusions}

The European Quality Labels in Chemical Sciences are an interesting factual example of how the Tuning methodology may be used by a transnational body - the European Chemistry Thematic Network - in order to promote quality assurance in the European Higher Education Area and even beyond its borders. In fact, the academic world largely welcomed the initiative. By the end of 2013, 146 European Quality Labels have been awarded to institutions and consortia coming from twenty-two European and three non-European countries, the latter being Morocco, the Russian Federation and Kazakhstan.

\section{Bibliography}

Chemistry Doctorate Eurolabel ${ }^{\circledR}$ Project. "A Framework for a Third Cycle Qualification in Chemistry." Last modified April 8, 2014. http://www. phdchem.eu.

"European Alliance for Subject-Specific and Professional Accreditation and Quality Assurance." Last modified March 30, 2014. http://www.easpa.eu. 
"European Association for Chemical and Molecular Sciences - European Chemist Designation." Last modified April 15, 2014. http://www.euchems.eu/nc/ members/european-chemist.html?sword_list\%5B\%5D=chemist.

—. Last modified April 15, 2014. http://www.euchems.eu/about.html.

"European Chemistry Thematic Network." Last modified March 21, 2014. http:// ectn-assoc.cpe.fr/.

—. "Recommendations for the Third Cycle." Last modified March 21, 2014. http://ectn-assoc.cpe.fr/chemistry-eurolabels/doc/officials/Off_EDL061017_ Eurodoctorate200611V1.pdf.

—. "The Chemistry "Eurobachelor ${ }^{\circledR}$." Last modified March 21. http://ectnassoc.cpe.fr/chemistry-eurolabels/doc/officials/Off_EBL070131_ Eurobachelor_Framework_2007V1.pdf.

- "The Chemistry «Euromaster ${ }^{\circledR}$." Last modified March 21. http://ectn-assoc. cpe.fr/chemistry-eurolabels/doc/officials/Off_EML060930_Euromaster_ Framework_200609V1a.pdf.

European Commission. "A Framework for Qualifications of the European Higher Education Area.” Last modified April 15, 2014. http://www .ehea.info/Uploads/ qualification/050218_QF_EHEA.pdf.

_. "Bologna Process - European Higher Education Area. How does the Bologna Process work.” Last modified April 15, 2014. http://www.ehea.info/ article-details .aspx?ArticleId=5

- "Bologna Process - European Higher Education Area." Last modified April 15, 2014. http://www .ehea.info/.

__. "European Credit and Accumulation System.” Last modified April 16, 2014. http://ec.europa.eu/education/tools/ects_en.htm.

_. "European Qualifications Framework for Lifelong Learning." Last modified October 21, 2013. http://ec.europa.eu/eqf/home_en.htm

—. "Making the Most of Our Potential: Consolidating the European Higher Education Area (Bucharest 2012)." Last modified April 15, 2014. http://www. ehea.info/Uploads/\%281\%29/Bucharest\%20Communique\%202012\%281\%29. pdf.

—. "The Bologna Process 2020 - The European Higher Education Area in the New Decade (Leuven/Louvain-la-Neuve 2009).” Last modified April 15, 2014. http://www.ehea.info/Uploads/Declarations/Leuven_Louvain-la-Neuve_ Communiqu\%C3\%A9_April_2009.pdf.

- "The European Higher Education Area - Achieving the Goals (Bergen 2005)." Last modified April 15, 2014. http://www.ehea.info/Uploads/ Declarations/Bergen_Communique1.pdf

- "The Framework of Qualifications for the European Higher Education Area - Dublin Descriptors.” Last modified April 15, 2014. http://www.ehea.info/ Uploads/Documents/QF-EHEA-May2005.pdf.

Tuning Project. "Reference Points for the Design and Delivery of Degree Programmes in Chemistry." Accessed May 2, 2014. http://www.unideusto.org/tuningeu/ images/stories/Publications/CHEMISTRY_FOR_WEBSITE.pdf. 